\section{Mass media awareness campaign and the prevention of the spread of Lassa fever in the rural communities of Ebonyi State, Nigeria: Impact evaluation}

\author{
Joseph Oluchukwu Wogu \\ Department of Mass Communication, \\ University of Nigeria, Nsukka, Nigeria
}

\begin{abstract}
This paper investigates the impact of media campaign on the prevention and spread of Lassa fever in Ebonyi state. 354 respondents were randomly selected from six rural communities in the state as study sample, while structured questionnaires were used for collecting data. SPSS version 20.0 was used to analyze the data. Results of analysis reveal that the media campaign has rural reach but has little or no impact. The results also reveal that the campaign failed to create appropriate awareness of the disease, its preventive/curative health behaviors. It further reveals that there are no health behavior modifications among the people because of the campaign. Therefore, this paper recommends the modification of media contents to incorporate the required preventive/curative health behaviors. Secondly, mandatory mass media awareness campaign and jingles in every news hour is recommended.
\end{abstract}

\section{Introduction}

Lassa fever is a non-gender or non-age prone endemic zoonotic and acute viral hemorrhagic disease that is caused by a single-stranded RNA virus of the family Arena viridae. ${ }^{1}$ According to McCormick $^{2}$ and Ogbu et al., ${ }^{2}$ Lassa fever has claimed 5000 to 10,000 lives worldwide with an estimated two million infections every year, while West Africa alone records an estimated 300,000 to 500,000 cases of Lassa fever hundreds of deaths. Although many scholars erroneously hold that Lassa fever was discovered first in Nigeria when two missionary nurses died of it in 1969, the root of the disease is traceable to its discovery in Sierra Leone in the 1950s. Adefisan (2014: 166) captured this in the following words: ${ }^{3}$ Lassa fever as an endemic acute viral hemorrhagic disease was first discovered in Sierra Leone in the 1950s but the virus responsible for the infection was not known until 1969 when it claimed the lives of two missionary nurses. This fever was named after a village called Lassa in Borno State, Nigeria.

After, there were subsequent outbreaks of the disease in Liberia, Sierra Leone, and in the United States of America. In each of these cases, many lives were lost. ${ }^{4}$ According to Olalekan ${ }^{5}$ and Ehichioya et al., ${ }^{6}$ Nigeria is not an exception. The epidemic spread like wide fire in Kano, Nassarawa, Plateau, Kebbi, Edo, Oyo, Ogun, Abuja -the Federal Capital Territory, Onitsha in Anambra, Abo Mbaise and Owerri in Imo State, and many places in Ebonyi state between 2005 and 2010. ${ }^{7}$ Cases of the epidemic were also reported in Benue State in January 2013 with casualties. $^{8}$

The epidemic claims the lives of over 3000 Nigerians annually. ${ }^{9-11}$ This is because the popular carrier/transmitter of the Lassa virus - mastomysrat lives in and around human homes. The virus is transmitted through contact with its excreta deposited around homes, ${ }^{12}$ on human food and wastes, and poorly stored food. ${ }^{4}$ Many homes equally eat the rodents as meat without knowing that Lassa fever is transmitted through it. ${ }^{3}$ However, Olalekan blamed poor sanitation, overcrowding, inadequate resources to manage cases, lengthy dry season, weak health system, poor public enlightenment program, and most importantly poor epidemic preparedness for the Lassa fever prone high mortality rate. ${ }^{5}$

Adefisan observed that the first outbreak of Lassa fever in Ebonyi state, ${ }^{3}$ Nigeria occurred from January 1 to March 25, 2012. Federal Teaching Hospital, Abakaliki (FETHA) reported the first case on January 9, 2012 to the Ebonyi State and Federal Ministry of Health $(\mathrm{MoH})$ involving a 25-year-old Youth Corper who was serving in Rivers State, Nigeria but returned home for holidays. Unfortunately, six medical personnel that treated the Corper became infected also. ${ }^{13}$ This suffices to say that the disease was transferred to Ebonyi state from Rivers state both in Nigeria. The virus began to spread like wild fire such that 14 persons died of the disease with 83 other record of suspected cases between January and April, 2016 alone. This led to the construction of the first South-East Virology center within the premises of the Federal Teaching Hospital, Abakaliki (FETHA) in 2016 and the declaration of state of emergency in the health sector by Ebonyi state government. They set up a Surveillance and Response Team to all the places discovered to have been ravaged by the deadly disease and established an awareness team of three Special Assistants to Governor David
Correspondence: Joseph Oluchukwu Wogu, Department of Mass Communication, University of Nigeria, Nsukka, Nigeria.

Tel.: +2348038726595

E-mail: Joseph.Wogu@unn.edu.ng

Key words: Lassa fever, curative and preventive, media, contents, awareness, and behavior modification

Conflict of interest: the author declares no potential conflict of interest.

Funding: none.

Received for publication: 21 February 2018. Accepted for publication: 23 August 2018.

This work is licensed under a Creative Commons Attribution NonCommercial 4.0 License (CC BY-NC 4.0).

(C) Copyright J.O. Wogu, 2018

Licensee PAGEPress, Italy

Journal of Public Health in Africa 2018; 9:882 doi:10.4081/jphia.2018.882

Umahi on Primary Health Care. They embarked on community sensitization and campaigns across the 13 Local Government areas of the state via town unions, traditional rulers, and religious institutions.

The sensitization and awareness campaign were to sensitize the populace on the cause of Lassa fever, its symptoms, consequences, and prevention methods. The media (particularly social media, radio and television) was used as a veritable instrument for creating the needed awareness and Lassa fever health education, ${ }^{14-17}$ although some scholars argue that the use of social media is an exclusive reserve of the educated. Ebonyi state government adopted inclusive media institutions, i.e. television stations, radio stations, and newspapers together with other traditional means of mass mobilization to create proper awareness of Lassa fever epidemic among the rural communities. These institutions particularly the television and radio stations adopted native vernacular or language as their means of communication. This study, therefore, is poised to assess the level of awareness of Lassa fever among residents of different rural communities in Ebonyi state in the light of media sensitization campaign in the state, and the impact of the campaign on their environmental health behaviors.

\section{Research question}

In pursuit of the goals of this paper, the following questions guide the inquiry:

a. Is the Lassa fever media awareness in Ebonyi state accessible to the rural populace? 
b. Has the media campaign created a reasonable level of mass awareness of Lassa fever epidemic, causes, effects, and prevention in the rural communities of Ebonyi state?

c. Has the awareness made any positive impact on the environmental health behavior of rural people in Ebonyi state?

\section{Significance of the study}

The study will enable relevant agencies concerned with eradicating Lassa fever in Ebonyi state and Nigeria in general to appraise the media framework for possible modification or modernization. The study exposes the rural people's perception of the media as an institution concerned with people's welfare and from there highlight the potency of the media as instrument of mass education and mobilization for public policy implication in the state.

\section{Scope of the study}

The study covers the three geo-political zones that constitute Ebonyi state, although rural communities were randomly selected as areas of study. Thematically, the study is restricted to Lassa fever media awareness and its impact on the environmental health behavior of rural inhabitants.

\section{Literature review}

According to Tobin et al.: ${ }^{18}$ Lassa fever is an acute viral hemorrhagic illness caused by Lassa virus, a member of the virus family Arenaviridae. According to Yunusa and Egenti, ${ }^{19}$ Lassa fever is characterized by fever, muscle aches, sore throat, nausea, vomiting, chest and abdominal pain. It is consistent with persistent, asymptomatic infection, with profuse urinary virus excretion in Mastomysnatalensis, the ubiquitous and highly commensal rodent host. It is dominant in the literature that rodent is the primary carrier and distributor of the Lassa fever virus, and transmit the virus through urinary and feces excretion. ${ }^{20,21}$ It is transmitted to man through contact with the excreta deposited in foods, provisions (like bread and biscuit), during hunting and processing of rats for consumption, during care for infected sick relatives or in health care settings. $^{22,23}$

Kelly et al. ${ }^{24}$ observed that Lassa fever is a rural communities' prone epidemic due to their population. Research seems to validate the notion that greater proportion of people live in the rural communities, where poverty, ignorance, and limited access to mass media and orthodox medicine prevail. However, Olalekan argues that rats are ubiquitous in human households whose existence is prevalent in urban areas and cities. ${ }^{5}$ Factors such as unplanned urbanization, population explosion in the cities and urban areas, indiscriminate refuse disposal, poor personal hygiene and overcrowded housing contribute to their movements and habitation in the urban setting. ${ }^{25}$ Thus, it is always a harvest of deaths for such communities to experience an outbreak of Lassa fever epidemic. These deaths include patients, medical staff, surgeons, nurses and other trained laboratory personnel. ${ }^{26,27}$ Yunusa and Egenti, ${ }^{19}$ and Ogbu, ${ }^{3}$ observe that the endemic is responsible for over 5,000 deaths annually in West Africa. According to WHO report, ${ }^{28}$ over 100,000 lives were lost to Lassa fever between 1969 and 2012, with many unrecorded deaths that occurred in rural areas.

Ajayi et al. ${ }^{29}$ argued that although relevant agencies employed coordination, laboratory testing, active surveillance, community mobilization, contact and suspected case evaluation and case management as means of eradicating the epidemic, poor public sensitization and awareness of epidemic is responsible for the high fatality rate recorded so far. They suggested the establishment of effective disease awareness, public enlightenment on personal hygiene, notification and prompt action system as one of the means of eradicating it. Concurring to this observation, Aniwada and Obionu observed that correct knowledge of the epidemic and its dynamics, disease surveillance and notification need to be improved..$^{30}$ Nnebue et al. ${ }^{31}$ blame poor surveillance system, poor funding, inefficient laboratory, poor reporting, communication problems, absence of trained medical personnel, and vertical programs doing parallel reporting for the high fatality and/or mortality in Lassa fever outbreaks.

However, Olayinka et al., ${ }^{32,33}$ Ochei et al., ${ }^{34}$ and Reuben and Gyar, ${ }^{35}$ observed that the rate of awareness of Lassa fever disease in Nigeria particularly among the Owo people of Ondo State and Irrua households in Edo State is very high. Nevertheless, they argue that it may be so because these areas were hotspots for Lassa fever outbreaks.

Tobin et al., ${ }^{18}$ Idris et al. ${ }^{36}$ and Ogoina et $a$. $^{37}$ in their study of public and private health institutions in Nigeria observed that there is high level of awareness, and good knowledge of Lassa fever epidemic among health care workers. However, they exhibit poor knowledge of injection safety and complained of inadequate resources to practice standard precautions. Furthermore, Amoran and Onwube made similar observation that majority of the health care workers interviewed were unable to identify and/or explain Lassa fever vaccinations, post-exposure prophylaxis, and surveillance for emerging diseases. ${ }^{38}$ In a more distinct form, Adefisan and Adebimpe observed that both the literate and illiterate rural dwellers irrespective of gender lack proper awareness that rat is the vector of Lassa fever and the dynamics of the epidemic. . $^{3,16}$ This leads to uninformed fears among them and the refusal of health care workers to engage in humanitarian intervention in cases of others' infection with the disease for fear of being infected.

Adebimpe et al. observed that there is no health behavior modification among Nigerian communities in spite of the perceived awareness of the epidemic. ${ }^{14}$ The culture of poor refuse disposal, poor attitude to fumigation activities and poor personal and environmental hygiene persist. ${ }^{15}$ Majority of the households studied are still parking household loads and food items in the same place without covering food items properly, while the unhealthy disposition of daily accumulated refuse among the households remained the same. Most of the rural and urban residents still eat food contaminated by rodents through contacts or even eating by rodents. ${ }^{35}$

\section{Framework of analysis}

This paper adopts mediatisation theory as its framework of analysis. The theory focuses on the influence media exerts on a variety of social phenomena. As developed by Strömbäck, ${ }^{39}$ Cottle, ${ }^{40}$ Schulz, ${ }^{41}$ Thompson, ${ }^{42}$ and others, it views the media as an independent institution with a logic of its own that other social institutions have to assimilate or accept. The media becomes an integrated part of other social institutions like politics, work, family, and religion because their institutional activities are performed through interaction and mass media. The media coordinate these activities and their mutual interaction, and from there alter or harmonize their original values. ${ }^{43}$ The framework is therefore concerned with changing the inner workings of other social entities and their mutual relationships (Hernes, 1978: 181).

The applicability and relevance of mediatisation framework of analysis to this study lies in its ability to highlight and investigate the ability of the media in Ebonyi state to change not only the Lassa fever awareness status of the rural people but also to change their health behavior. Fundamental attention is given to formatting of communication (i.e. style, content and language) and its impacts on individual behavior. Therefore, the theory provides relevant guide for assessing the impact of the media towards the control and eradication of Lassa fever in Ebonyi state, evaluating the nature and contents of media cam- 
paign and their impact for possible moderation or changes.

\section{Materials and Methods}

\section{Research design}

The paper adopts descriptive survey design and used structured questionnaire for primary data collection. Six rural communities were randomly selected from the three senatorial districts of Ebonyi state as follows: Ebonyi North comprising Umuezekoha and Egwudulegu communities; Ebonyi Central comprising Aguiyima and Azuakparata communities; and Ebonyi South comprising Obiozara and Mgbelaeze communities. Experts in the Faculties of Arts and Social Sciences, University of Nigeria, Nsukka tested the validity of the research instrument i.e. the questionnaire. On the other hand, a test-retest method was carried out within an interval of two weeks in two rural communities of Anambra state to test its reliability of the instrument and the questions therein. The correlation analysis of responses from the two set of tests showed a reliability of more than 0.95 .

In addition, secondary data was generated from relevant published and accessible materials in public and private libraries such as books, government publications, conference and workshop papers, Newspapers and Magazines, and internet materials etc.

\section{Population of study}

The study population included all the residence of the six communities selected in addition to all the health care workers in the primary health care facilities situated there. According to 2006 National Population figure, 3216 people reside in these communities.

\section{Sample size and sampling technique}

The paper determined its sample size with the aid of Yaro Yemani formula for determining sample size, which is:

where $\mathrm{n}=$ Sample size
$\mathrm{N}=$ Population of the study

$\mathrm{e}=$ margin of error [which stands for 0.05 in this study].

$=\mathrm{a}$ constant

Therefore, $\mathrm{n}=3216=3216$

$21+3216(0.05) 1+3216(0.0025)$

$\mathrm{n}=3216=3216$

$1+8.049 .04$

$\mathrm{n}=355.75$, which is approximately 356 .

356 being the study sample were divided into 6 where in 59 questionnaires were distributed equally in each of the communities leaving a balance of 2 . The questionnaires were distributed randomly with the aid of research assistants and all were recollected after completion. To resolve ethical issues, the purpose of the research was explained while assurance of anonymity and confidentiality was given to them for obtaining informed consent. In addition, the contents of the questionnaire were explained to those that could neither read nor write, and their responses to the questions marked by research assistants.

\section{Method of data analysis}

The data collected during the fieldwork were analyzed with the aid of Statistical Package for Social Sciences (SPSS) version 20.0 to determine statistical central tendencies and deviations in the respondents' answers to questions contained in the questionnaire. However, the demographic data of the respondents was analyzed using frequency tables and percentages.

\section{Data collection and analysis}

Data presentation and its analysis are presented here under the following: a table of data containing respondents' demographic details and their \% interpretations; SPSS variance analysis of the data generated for purposes of generalization.

An analysis of Tables 1 and 2 reveals that 208 respondents representing 58.8\% are female while 146 respondents i.e. $41.2 \%$ are males. Similarly, $20.0 \%$ of the respondents fall within 18 and 34 years, $39.9 \%$ of the respondents fall within the age bracket of 35 and 50 years, $21.4 \%$ fall within 51 and 65 years, while $9.7 \%$ are the age 66 years and above. Furthermore, $66.7 \%$ of the respondents are moderately literate with high school education, $19.8 \%$ acquired higher education, while $13.5 \%$ are illiterate. A review of these statistics shows that the research is gender sensitive, has informed respondents, and possesses reliable and valid observation.

The SPSS univariate analysis of responses to questions interrogating people's awareness of Lassa fever in the rural communities of Ebonyi state reveals a total grand mean of 4.07 with a standard error of 0.064 and a standard deviation of 1.255 . The confidence interval of the responses lies between 3.941 and 4.194, which is within the $95 \%$ confidence interval of the difference (variable 1, Table 3). According to its Tests of Between-Subjects Effects, the mean differences of the entire responses show a significant difference of 0.000 , whereas the mean difference should be significant at 0.05 levels.

Furthermore, the analysis of responses to questions interrogating people's knowledge of the symptoms of Lassa fever reveals a total grand mean of 2.59 with a standard error of 0.064 and a standard deviation of 1.159 . The confidence interval of the responses lies between 2.460 and 2.698, which is within the $95 \%$ confidence interval of the difference (variable 2, Table 3). According to its Tests of Between-Subjects Effects, the mean differences of the entire responses show a significant difference of 0.000 , whereas the mean difference should be significant at 0.05 levels.

The analysis further reveals that $31.2 \%$ i.e. 312 respondents learnt about Lassa Fever through radio and TV programs, while others learnt about it through other sources like churches, schools, and civil society organizations.

The analysis of responses to questions interrogating people's knowledge of the required personal and family hygienic/health behaviors needed to prevent Lassa fever reveals a total grand mean of 2.43 with a standard error of .054 and a standard deviation of 1.022 . The confidence interval of the responses lies between 2.326 and 2.538 , which is within the $95 \%$ confidence interval of the difference (variable 3,

Table 1. Summary of respondents' demographic data.

\begin{tabular}{|c|c|c|c|c|c|c|c|c|}
\hline \multirow[t]{2}{*}{ N. } & \multirow[t]{2}{*}{ Senatorial District } & \multirow[t]{2}{*}{ CommunitiesStudied } & \multicolumn{3}{|c|}{ Population/Gender } & \multicolumn{3}{|c|}{ Respondents/Gender } \\
\hline & & & Total & Male & Female & Total & Male & Female \\
\hline 1 & Ebonyi North & 2 & 997 & 411 & 586 & 118 & 45 & 73 \\
\hline 2 & Ebonyi Central & 2 & 1318 & 569 & 749 & 118 & 62 & 56 \\
\hline 3 & Ebonyi South & 2 & 901 & 333 & 568 & 118 & 39 & 79 \\
\hline & Total & 6 & 3216 & 1362 & 1854 & 354 & 146 & 208 \\
\hline
\end{tabular}


Table 3). According to its Tests of BetweenSubjects Effects, the mean differences of the entire responses shows a significant difference of 0.000 and 0.031 respectively, whereas the mean difference should be significant at 0.05 levels. $91.2 \%$ of the respondents observed that the various media awareness campaign programs are bereft of the details of Lassa fever infections, its curative measures, treatment centers, and preventive behaviors.

The analysis of responses to questions interrogating if the respondents engage themselves in health behavior modification in terms of regular hand washing, structural and goods arrangement in the house due to their awareness of Lassa fever reveals a total grand mean of 2.43 with a standard error of .054 and a standard deviation of 1.022. The confidence interval of the responses lies between 2.326 and 2.538, which is within the $95 \%$ confidence interval of the difference (variable 4, Table 3). According to its Tests of Between-Subjects Effects, the mean differences of the entire responses shows a significant difference of 0.000 and 0.031 respectively, whereas the mean difference should be significant at 0.05 levels.

Similarly, the analysis of responses to questions interrogating if the respondents attend medical check-up and other Lassa fever preventive clinical therapy reveals a total grand mean of 2.31 with a standard error of .054 and a standard deviation of 1.026. The confidence interval of the responses lies between 2.213 and 2.409, which is within the $95 \%$ confidence interval of the difference (variable 5, Table 3). According to its Tests of Between-Subjects Effects, the mean differences of the entire responses show a sig. difference of 0.000 , whereas the mean difference should be significant at 0.05 levels.

\section{Discussion}

This paper investigated the impact of mass media awareness campaign on the prevention of the spread of Laser Fever in the rural communities of Ebonyi State. In pursuit of this objective, the paper investigated the level of people's awareness of Lassa fever disease, which reveals a total grand mean of 4.07 with the mean differences of the entire responses showing a significant difference of 0.000 . The mean difference should be significant at 0.05 levels. Therefore, the differences in their responses are insignificant in this case because the 0.000 difference is equivalent to no adjustments. Consequently, the grand mean response of 4.07 representing 'Agreed' in our Linkert scale measure is accepted. This implies that the majority of the respondents are aware of Lassa fever disease. According to their responses, $31.2 \%$ i.e. 312 respondents learnt about Lassa fever through radio and TV programs.

However, in spite of the acknowledged awareness of Lassa fever disease, analysis of their responses to the question interrogating people's knowledge of the symptoms of Lassa fever reveals a total grand mean of 2.59 with the mean differences of the entire responses shows a significant difference of 0.000 . The mean difference should be significant at .05 levels. Therefore, the differences in their responses are insignificant in this case because the 0.000 difference is equivalent to no adjustments. Consequently, the grand mean response of 2.59 representing 'Disagreed' is accepted. This implies that majority of the respondents lack appropriate knowledge of the symptoms of Lassa fever. Simply put, they have heard about it but do not know how to detect its infection.

Similarly, the analysis of responses to questions interrogating people's knowledge of the required personal and family hygienic/health behaviors needed to prevent Lassa fever reveals a total grand mean of 2.43 and mean differences showing a significant difference of 0.000 and 0.031 respectively. The mean difference, which should be significant at 0.05 levels is insignificant in this case. Therefore, the grand mean response of 2.43 representing 'Disagreed' is accepted, and implies that the respondents lack the appropriate knowledge of the required personal and family hygienic/health behaviors needed to prevent Lassa fever.

The analysis also reveals a total grand mean of 2.43 with mean differences of the entire responses showing a significant difference of 0.000 and 0.031 respectively, for responses to the statement that the respondents engage themselves in health behavior modification in terms of regular hand washing, structural and goods arrangement in the house due to their awareness of Lassa fever. The mean differences, which should be significant at 0.05 levels is insignificant in this

Table 2. Socio-demographic data on age and education of respondents.

\begin{tabular}{lccc}
\hline Factor & Categories & Response frequency & \\
Age Distribution & $18-34$ yrs & 71 & 20.0 \\
& $35-50$ yrs & 141 & 39.9 \\
& $51-65$ yrs & 76 & 21.4 \\
Educational Qualification & $>66$ & 66 & 18.6 \\
& PG Degrees & 30 & 8.4 \\
& BSc/HND & 57 & 16.1 \\
& OND/NCE & 103 & 29.1 \\
& SSCE/GCE & 82 & 23.2 \\
& FSLC & 54 & 15.3 \\
& No Education & 28 & 7.9 \\
\hline
\end{tabular}

Table 3. Grand mean. Dependent variables: Responses.

\begin{tabular}{lcccc} 
Variable & Mean & Standard error & Lower Bound & 95\% confidence interval \\
\hline 1 & 4.068 & 0.064 & 3.941 & 4.194 \\
2 & 2.579 & 0.060 & 2.460 & 2.698 \\
\hline 3 & 2.432 & 0.054 & 2.326 & 2.538 \\
4 & 2.432 & 0.054 & 2.326 & 2.538 \\
\hline 5 & 2.311 & 0.050 & 2.213 & 2.409 \\
\hline
\end{tabular}


case. Therefore, the grand mean response of 2.43 representing 'Disagreed' is accepted, and implies that there is no health behavior modification in terms of regular hand washing, structural and goods arrangement in the house in spite of people's awareness of Lassa fever in the rural communities of Ebonyi state.

The analysis also reveals a total grand mean of 2.31 with the mean differences of the entire responses to the statement that respondents attend medical checkup and other Lassa fever preventive clinical therapy showing a significant difference of 0.000 . The mean difference, which should be significant at .05 levels is insignificant in this case. Therefore, the grand mean response of 2.31 representing 'Disagreed' is accepted, and implies that majority of the people do not attend medical check-up and other Lassa fever preventive clinical therapy in the rural communities of Ebonyi state.

\section{Findings, conclusions and recom- mendations}

In its investigation of the impact of mass media awareness campaign on the prevention of the spread of Laser Fever in the rural communities of Ebonyi State, this paper made the following findings:

There is high-level awareness of Lassa fever disease in the rural communities of Ebonyi state but only 31.2\% learnt about it through radio/TV programs.

Majority of the respondents lack the appropriate knowledge of the symptoms of Lassa fever.

Majority of the respondents lack the appropriate knowledge of the required personal and family hygienic/health behaviors needed to prevent Lassa fever.

There is no health behavior modification in terms of regular hand washing, structural and goods arrangement in the house in spite of people's awareness of Lassa fever in the rural communities of Ebonyi state.

Majority of the respondents do not attend medical check-up and other Lassa fever preventive clinical therapy.

Consequent upon the above findings, this paper concludes that media Lassa fever awareness campaign is accessible to the rural populace but it has little or no impact on the eradication or prevention of the spread of the disease in the rural communities of Ebonyi state. It did not create a reasonable level of mass awareness of Lassa fever epidemic, symptoms, preventive health behaviors, and the curative measures in the rural communities of Ebonyi state. Consequently, people do not attend clinical examination or test. This is because of lack of enough media coverage and appropriate contents of Lassa fever in the campaign.
This paper, therefore, recommends appropriate massive media awareness campaign and modification of media campaign contents to incorporate the symptoms, required preventive health behavior, curative measures and centers of Lassa fever treatment. Government should introduce a health policy of playing encompassing media awareness campaign and jingles in every news hour in both public and private owned media.

\section{References}

1. Viral haemorrhagic fevers consortium. Lassa fever. 2013. Available from: http://www.vhfc.org/lassa_fever

2. McCormick JB. Lassa fever. In: Saluzzo JF, Dodet B (Eds.). Emergence and control of rodent-borne viral diseases. Amsterdam: Elsevier; 1999. pp 177-795.

3. Ogbu O, Ajuluchukwu E, Uneke CJ. Lassa fever in West African sub-region: an overview. J Vector-Borne Dis 2007;44:1-11.

3. Adefisan AK. The Level of Awareness that Rat is a Vector of Lassa Fever among the Rural People in Ijebu-North Local Government, Ogun State, Nigeria. J Educ Pract 2014;5:166-70.

4. Oyetimi K. Lass fever: The hidden epidemic is here. Sunday Tribune. (5 February 2012). pp.2-3.

5. Olalekan AW. Pre-epidemic preparedness and the control of Lassa fever in Southern Nigeria. Res J Health Sci 2016;4;243-54

6. Ehichioya DU, Hass M, Olschlager S, et al. Lassa fever, Nigeria, 2005-2008: Emerging Infectious Disease. 2010. Abuja: Centers for Disease Control and Prevention. Available from: http://wwwnc.cdc.gov/eid/article/16/6/ 10-0080.htm

7. Victor K, Nwadiaro EC. Lassa Fever: Focus On Medical/Academic Research and Popular Press Depiction. Global J Arts Hum Soc Sci 2016;4:29-36.

8. Duru P, Olowoopejo M. Lassa fever: FG releases 4,500 doses of drugs for Benue. 2013. Available from: http:/www.vanguardngr.com/2013/01/1 assa-fever-fg-releases-4500-do

9. Ibeabuchi C. Lassa fever Kills 3, 000 Nigerians annually. The News (26 March 2012). p 7.

10. Akpede G. 22 die of Lassa fever in Edo. Interview granted to the News Agency of Nigeria (NAN) in Irrua, Edo State. 26 February 2012.

11. Oguntola A. Expert advised on Lassa fever prevention. The Nigerian Tribune.
27 September 2012. p.40.

12. Ogunyedeka A. Lassa fever Kills 3, 000 Nigerians annually. The News. 26 March 2012. p. 13

13. Ajayi NA, Nwigwe CG, Azuogu BN, et al. Containing a Lassa fever epidemic in a resource-limited setting: outbreak description and lessons learned from Abakaliki, Nigeria (January-March 2012). Int J Infect Dis 2013;17:e1011-6.

14. Adebimpe WO. Community awareness and perception towards rodent control: implications for prevention and control of Lassa fever in urban slums of Southwestern Nigeria. Malta J Health Sci 2015;3:26-32.

15. Adebimpe WO. Knowledge and preventive practices against Lassa fever among primary health care workers in Osun state. University of Mauritius Med J 2015;21:579-93.

16. Adebimpe WO. From a single case to epidemics: Fear and misconceptions militating against effective control of Ebola virus disease outbreak in SouthWestern Nigeria. Nig J Health Sci 2015;15:58-9.

17. Picard R, Yeo M. Medical and health news information in the UK media: the current state of knowledge. A report of the Reuters Institute for the study of Journalism. 2011.

18. Tobin E, Asogun D, Isah E, et al. Assessment of knowledge and attitude towards Lassa fever among Primary care providers in an endemic suburban community of Edo state: implications for control. J Med Med Sci 2013;4:3118.

19. Yunusa T, Egenti N. Understanding Lassa fever virus and diversification of the Rodent vector in the tropics. Abuja: Department of Medical Microbiology, University of Abuja Teaching Hospital. 2015.

20. Richmond JK, Baglole DJ. Lassa fever: epidemiology, clinical features and social consequences. $\mathrm{Br}$ Med J 2003;327:1271-5.

21. Salazar-Bravo J, Ruedas LA, Yates TL. Mammalian reservoirs of arena viruses. Curr Top Microbiol Immunol 2002;262:25-63.

22. Fisher-Hoch SP. Lessons from nosocomial viral haemorrhagic fever outbreaks. Br Med Bull 2005;73/74:12337.

23. Aranoff SA, Lacy MA, Smego RA. Viral hemorrhagic fevers. In Aranoff SA. (Ed.). Advances in paediatric infectious diseases. St. Louis: Mosby; 1997. pp. 21-53.

24. Kelly JD, Barrie MB, Ross RA, et al. Housing equity for health equity: A 
right based approach to the control of Lassa fever in post war Sierra Leone. BMC International Health and Human Rights 2003;13:2.

25. Hala IA. Health effect of slums: A consequence of urbanization. Scholarly Journal of Medicine 2013;3:7-14.

26. Safronetz D, Lopez JE, Sogoba N, et al. Detection of Lassa virus, Mali. Emerg Infect Dis 2010;16:1123-6.

27. Fisher-Hoch SP, Tomori O, Nasidi A, et al. Review of cases of nosocomial Lassa fever in Nigeria: the high price of poor medical practice. $\mathrm{Br}$ Med J 1995;311:857-9.

28. WHO. Lassa fever. A study of 23 hospital cases. Trans R Soc Trop Med Hyg 2012;66:390-401.

29. Ajayi NA, Nwigwe CG, Azuogu BN, et al. Containing a Lassa fever epidemic in a resource-limited setting: Outbreak description and lessons learned from Abakaliki, Nigeria. Int $\mathrm{J}$ Infect Dis 2012;17:e1011-6.

30. Aniwada EC, Obionu CN. Disease Surveillance and Notification, Knowledge and Practice among Private and Public Primary Health Care Workers in Enugu State, Nigeria: A Comparative Study. BJMMR 2016;13:1-10

31. Nnebue CC, Onwasigwe CV, Adogu
PO, Onyeonoro UU. Awareness and knowledge of disease surveillance and notification by health-care workers and availability of facility records in Anambra state, Nigeria. Niger Med J 2012;53:220-5.

32. Olayinka SI, Omotoso B, Osaretin AF, Adewuyi F. Awareness of Lassa fever in a rural community in South West Nigeria. School J Appl Med Sci 2015;3:1137-42.

33. Olayinka SI, Omotoso B, Alele FO, Adewuyi P. Awareness of Lassa Fever in a Rural Community in South West Nigeria. J Commun Health Res 2015;4:1-10.

34. Ochei O, Abejegah C, Okoh E, Abah SO. Housing Factors and Transmission of Lassa Fever in a Rural Area of Southsouth Nigeria. Gen Heal Med Sci 2014;1:15-20.

35. Reuben CR, Gyar SD. Knowledge, attitudes and practices of Lassa fever in and around Lafia, Central Nigeria. Int J Publ Health Epidemiol Res 2016;2:149.

36. Idris $\mathrm{BI}$, Inem $\mathrm{V}$, Balogun $\mathrm{M}$. Comparing the knowledge, attitude and practices of health care workers in public and private primary care facilities in Lagos State on Ebola virus disease. Pan Afr Med J 2015;22:1-19.
37. Ogoina D, Pondei K, Adetunji B, et al. Knowledge, attitude and practice of standard precautions of infection control by hospital workers in two tertiary hospitals in Nigeria. J Infect Prev 2015;16:16-22.

38. Amoran OE, Onwube OO. Infection Control and Practice of Standard Precautions Among Healthcare Workers in Northern Nigeria. J Global Infect Dis 2013;5:156-63.

39. Strömbäck J. Four Phases of Medianization. An Analysis of the Medianization of Politics. Paper presented to the ICA Conference in San Francisco May, 2007.

40. Cottle S. Mediatized Conflict. Maidenhead: Open University Press; 2006.

41. Schulz W. Reconstructing Mediatization as an Analytical Concept. Eur J Commun 20014;19:87-101.

42. Thompson JB. The Media and Modernity: A Social Theory of the Media. Cambridge: Polity Press; 1995.

43. Mazzoleni G, Schultz W. 'Mediatization' of Politics: A Challenge for Democracy? Pol Commun 1999;16:247-61. 